\title{
sciforum
}

Conference Proceedings Paper

\section{Geostatistical study of airborne geophysical data of the Tiouit mining area (Eastern Anti-Atlas, Morocco)}

\author{
Abdelhalim Miftah ${ }^{1, *}$, Driss El Azzab ${ }^{2}$, Ahmed Attou ${ }^{1}$ and Manar Ahmed ${ }^{3}$ \\ 1 Hassan First University of Settat, Faculty of Sciences and Technology, GMER Research Team, Settat, \\ Morocco ; attouahmed@hotmail.com (A.A) \\ 2 Sidi Mohamed Ben Abdellah University, Faculty of Sciences and Technology, SIGER Laboratory, Fez, \\ Morocco ; driss.elazzab@usmba.ac.ma (D.E.A) \\ 3 Ministry of Energy, Mines and Sustainable Development, Directorate of Geology, Rabat, Morocco; \\ a2manar@yahoo.fr (M.A) \\ * Correspondence: a.miftah@uhp.ac.ma (A.M.)
}

Received: date; Accepted: date; Published: date

\begin{abstract}
The main objective of the present work is to use principal component analysis (PCA) on the various airborne geophysical data, including gamma-ray spectrometry (concentrations of radioactive elements ${ }^{40} \mathrm{~K}$ and ${ }^{232} \mathrm{Th}$ ), magnetism (magnetization contrast due to magnetic susceptibility), and electromagnetism (apparent electrical resistivity) to describe the physicochemical behavior of the mining zones in operation as well as to prospect other zones favorable for exploration. This data's geostatistical study highlights the adequate principal component (PC) to visualize these geophysical variables. We chose PC4 to visualize the zones favorable for mining concentration because it describes the same physical and chemical characteristics represented by the Tiouit alteration zone. The collection and X-ray fluorescence analysis of 32 samples in the field yielded high grades of Arsenic (24 g/t), Copper (5.87\%), Iron (19.30 $\%)$, Lead (5.70\%), and Zinc (8.85\%).
\end{abstract}

Keywords: geophysics; magnetism; gamma-ray spectrometry; electromagnetism; geostatistics; Xray fluorescence; mining exploration; Eastern Anti-Atlas; Morocco.

\section{Introduction}

Geophysical methods respond to differences in the physical properties of rocks. In the area of interest, instruments are deployed in the field to measure variations in a physical parameter associated with variations in a subsoil's physical property. The ability of these methods to make these inferences remotely, without ground contact.

The study area is characterized by its strategic mining aspect considering the mining showings related to its geological, structural and geodynamic aspects which are located in the Jbel Saghro massif (Eastern Anti-Atlas). The site's choice was based on the geological map of Tiouit, known by the gold mine currently in shutdown. The genetic models proposed by different authors agree on an epithermal origin of copper porphyry type [1]. This type of deposit is characterized by a strong radioactive activity related to the circulation of hydrothermal fluids materialized by enrichment in ${ }^{40} \mathrm{~K}$ and depletion in ${ }^{232} \mathrm{Th}$, a low magnetic susceptibility due to the presence of iron oxides and a low apparent resistivity related to the presence of conductive minerals [2]. Three geophysical methods were used for automatic mapping. 
Magnetometry is one of the oldest geophysical methods. Variations in measurable magnetic intensity at the surface result from lithological changes are associated with the subsurface or igneous intrusions. Thus, aeromagnetic surveys provide unique geological information and serve as an indirect guide to stress-related epigenetic mineralization in surrounding rocks and direct detection of certain iron minerals [3].

Electromagnetic prospecting is based on electric current induction in conductive bodies when excited by a primary magnetic field. EM methods are used on a regional and prospective scale to direct electrically anomalous targets, including metallic sulphide and metallic oxide mineralization [4].

Potassium and thorium are measured in radiometric surveys as they are the main contributors to natural radioactivity and are present at various concentrations in rocks and soils. The derived element concentrations provide spatial images of the geochemistry of the upper layer of rocks and soils at a depth of about 30-45 cm, passing largely through vegetation. Hydrothermal alteration minerals (sericite, biotite, K-feldspar) can be detected and tracked using spectrometric data [5].

\section{Geological Context}

The Tiouit mining area (Figure 1) is part of the Jbel Saghro massif located between the Bou-Azzer El Graraa inlier in the South-West and the Ougnat massif in the North-East and it is structurally oriented East-West. It consists of five Precambrian inliers, of which those of Imiter, Sidi Flah, Boumalne, Kelâa Megouna, and Bouskour are made up of Precambrian terminal and Paleozoic terrains. The Paleoproterozoic of the region is limited to an ensemble of gneiss and amphibolite between Sekoura and Ouarzazate and a granite to the west of Imiter [6]. The Lower Neoproterozoic consists of a set of terrains of varied nature (sedimentary, volcano-sedimentary, and volcanic) located in the heart of the inliers mentioned above and traversed by various plutonic rocks [6]. Subsequently, the Middle Neoproterozoic is dominated by gabbros, quartz diorites, diorites, and andesites, especially in the Bouskour sector [7] that Leblanc [8] considered as the lateral equivalent of the Lower Precambrian II green rocks of Bou-Azzer. Finally, the terminal Neoproterozoic, which includes the Ouarzazate series defined by Boyer [9] and which overlies the basement formations in major unconformity.

\section{Materials and Methods}

\subsection{Geophysical data}

The geophysical data are made available to us by the Ministry of Energy, Mines, Water and Environment. They were carried out between November 1998 and May 1999. The flight lines have an NW-SE direction with a spacing of 500m, the tie-lines at $4000 \mathrm{~m}$ spacing from a NE-SW direction (Figure 1). In the present study, three geophysical methods were used.

\subsubsection{Magnetism}

Total magnetic field data was recorded in flight with a sampling interval of 0.1 seconds using an optically pumped Scintrex SC2 magnetometer with a minimum flight altitude of $30 \mathrm{~m}$, sensitivity $0.01 \mathrm{nT}$. The database from these maps allowed us to produce the map of the residual magnetic field. This map was reduced to the pole using the Fourier transform (Inclination $=42.37^{\circ}$; Declination $=-3.6^{\circ}$ ) [10].

\subsubsection{Electromagnetism}

Electromagnetic data were collected using a DIGHEMv electromagnetic system measuring inphase and quadrature components at five frequencies and three coplanar coils with a flight altitude of $30 \mathrm{~m}$. The raw data is recorded in digital form with a step of one measurement per 0.1 seconds. These data are then digitally processed at a rate of 10 samples per second to eliminate atmospheric effects and all other residual noise $[11,12]$. 


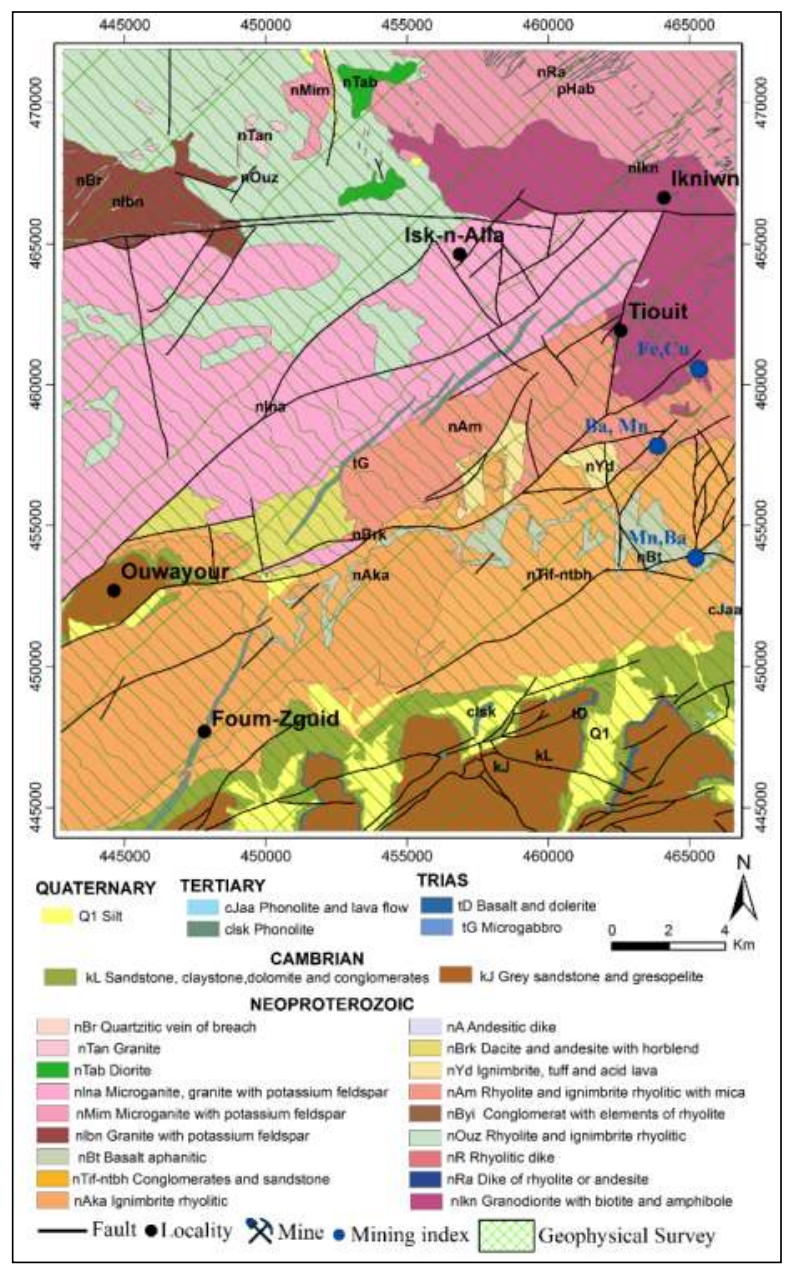

Figure 1. Geological map of Tiouit 1/50000 [13] superposed to geophysical survey.

\subsubsection{Gamma spectrometry}

Radiometric data were collected at a flight altitude of $60 \mathrm{~m}$ using a multichannel Exploranium GR 820 spectrometer (16.8 liter down, 4.2 liter up) which measures the energy range of the following five channels: Total Count (0.42-3 Mev), Potassium (1.373- $1.574 \mathrm{Mev})$, Thorium (2.414-2.816), Uranium (1.660-1.860 Mev) and Cosmic Background (3.00-6.00 Mev). Thanks to a gamma spectrometer, it is possible to estimate the energy of gamma photons emitted on the Earth's surface and their activity [14].

\subsection{Principal Component Analysis (PCA)}

The PCA [15] allows the analysis and visualization of data containing individuals described by several quantitative variables. It synthesizes this information into just a few new variables called principal components (PC). The variables used must be standardized. This is particularly recommended when the variables measured have different units [16]. A general formula can be applied to normalize the variables between an interval $[a, b]$ :

$$
\mathrm{V}_{\text {Nor }}=(\mathrm{b}-\mathrm{a}) \frac{\mathrm{v}-\mathrm{V}_{\text {Min }}}{\mathrm{V}_{\text {Max }}-\mathrm{V}_{\text {Min }}}+\mathrm{a}
$$

$V_{\text {Nor: }}$ the normalized value

$\mathrm{V}$ : the original value of the variable

$V_{\text {Min }}$ and $V_{\text {Max: }}$ the minimum and maximum values of the variable. 


\section{Results and Discussion}

\subsection{Residual magnetic field reduced to the pole}

The zone is highly magnetically disturbed, reflecting a heterogeneity linked to magnetized geological objects in the subsoil, varying from -360 to 400 with an average value of about $14.5 \mathrm{nT}$. The magnetic anomalies (Am) are subcircular and linear in shape with directions generally ENE-WSW, NNW-SSE, W-E, and NW-SE (Figure 2a). The map reduced to the pole has allowed identifying the lateral limits of the geological sources. We found a close relationship between the positive anomalies and the Precambrian age formations. The negative ones are related to relatively recent terrains, ranging from Paleozoic to Quaternary.
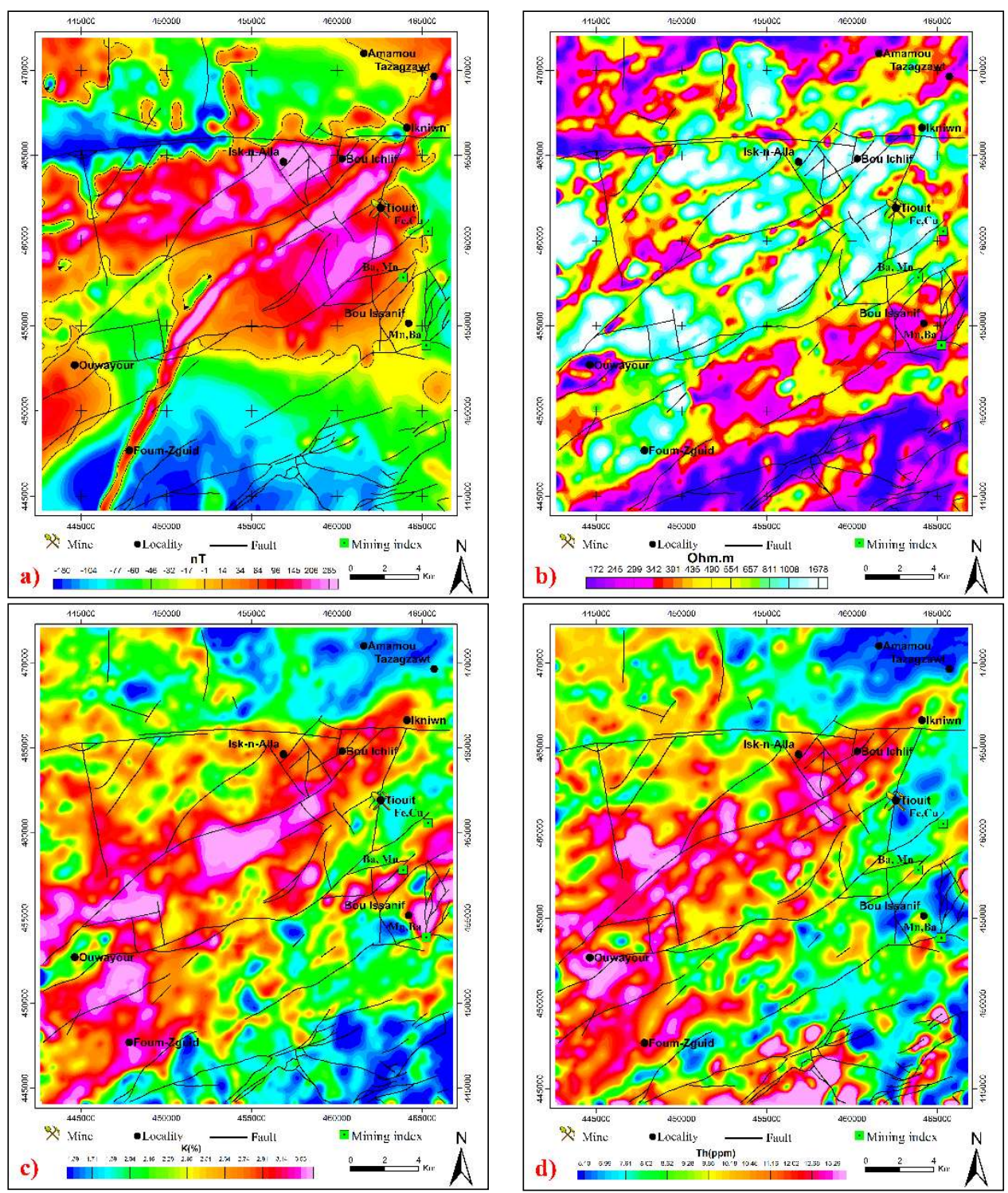

Figure 2. a) Residual magnetic field reduced to the pole. b) Electromagnetic anomalies of apparent resistivity of $7200 \mathrm{~Hz}$. c) Concentration in K (\%) and d) Concentration in Th (ppm).

\subsection{Electromagnetic anomalies of $7200 \mathrm{~Hz}$}

The $7200 \mathrm{~Hz}$ frequency map (Figure $2 \mathrm{~b}$ ) allows lateral mapping of shallow to shallow water anomalies. From a mining point of view, several electromagnetic anomalies coincide with very important mining showings, namely $\mathrm{Au}, \mathrm{Zn}, \mathrm{Pb}, \mathrm{Cu}, \mathrm{Fe}, \mathrm{Ba}$ and $\mathrm{Mn}$. Examination of the $7200 \mathrm{~Hz}$ 
apparent resistivity map (Figure $2 b$ ) shows different types of anomalies with point, elongated, axial, circular to subcircular shapes and with resistive and conductive variants from 19 to 3900 with a mean value of about $625 \mathrm{Ohm} . \mathrm{m}$. Generally, all of these resistant anomalies are concentrated in the Tiouit zone center with a NE-SW Pan-African direction. They have a punctual aspect and tend to interfere with becoming elongated; this finding can be explained by a deep origin that gave rise to these anomalies.

\subsection{Concentrations in $\mathrm{K}(\%)$ and $\mathrm{Th}(\mathrm{ppm})$}

The potassium concentration map (Figure 2c) shows a minimum value of $0.863 \%$ of Cambrian sandstone, clay, dolomitic and conglomeratic terrains, and a maximum value of about $4.555 \%$ due to Neoproterozoic formations located at the level of microgranites and granite with potassium feldspar. We also note that the triassic Foum-Zguid dykes of microgabbro, basalt and dolerite nature represent a relatively high value of $4.205 \%$. The last two formations represent a maximum average value of $2.770 \%$.

The Thorium concentration map (Figure 2d) shows that the Quaternary formations of alluvial and Cambrian nature of argillite, dolomite, and conglomerate have a minimum value $2.54 \mathrm{ppm}$. The Cambrian terrains represent maximum and average maximum values of 14.749 and 10.83 ppm, respectively. The Neoproterozoic formations belonging to the Ouarzazate Group, rhyolitic, and ignimbritic in nature have a value of $22.90 \mathrm{ppm}$.

\subsection{Principal Component Analysis (PCA)}

In this work, we have standardized the geophysical data to a range [0, 1]. After applying PCA, the eigenvector matrix is used to select the most suitable PC for the visualization of the desired information (Figure 3).

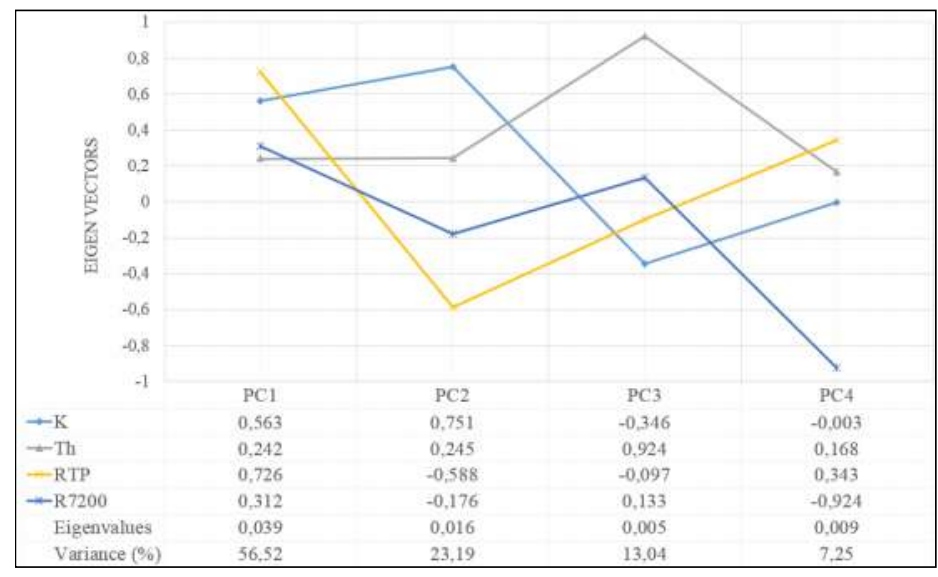

Figure 3. Graphical illustration of the eigenvector matrix resulted from geophysical data.

The examination of the eigenvectors obtained from the application of PCA on geophysical data leads to the conclusion that:

- CP1: represents a total variance of the order of $57 \%$ and high and positive eigenvector values for all geophysical data. The visualization of CP1 clearly shows that all information is presented with a dominance of the magnetic data $(+0.726)$ and the $\mathrm{K}$ concentration (+0563) (Figure 4a).

- $\quad$ CP2: It shows high and positive eigenvector values for the $\mathrm{K}$ concentration $(+0.751)$ and a mean contribution of the Th concentration. The magnetic and electromagnetic data have negative values. $\mathrm{CP} 2$ will therefore be used to visualize the variation of the spectrometric data (Figure $4 b$ ). 
- CP3: It shows high and positive eigenvector values for Th concentration (+0.924) and a low contribution from other geophysical parameters. CP3 will be very useful for mapping Thorium-rich zones (Figure 4c).

- CP4: we find eigenvector values of $-0.003,0.168,0.343,-0.924$ for $\mathrm{K}$, Th, RTP, and R7200, respectively. These values show that component 4 shows an inverse variation in the physical properties of the deposit being searched so that the resulting map will be multiplied by -1 . Overlaying it with the mineral occurrences being mined confirms the location and genetic model of the old Tiouit mine proposed by previous studies and other zones likely to contain mineralization (Figure $4 \mathrm{~d}$ ).
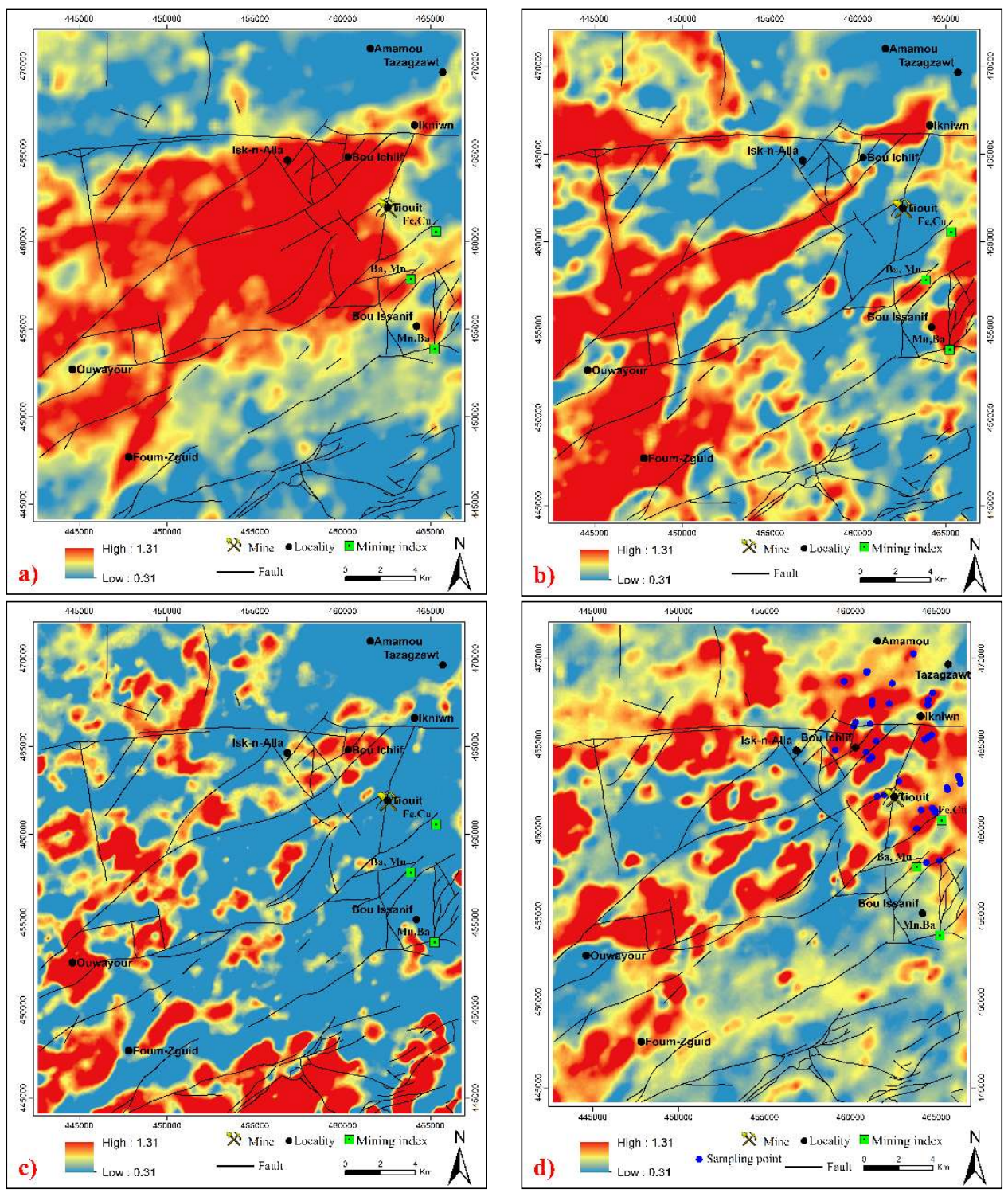

Figure 4. Principal components of geophysical data. a) CP1, b) CP2, c) CP3, D) CP4 multiplied by -1.

\subsection{Verification of mining zones by geochemical analysis}

To validate the method, we conducted a field verification by collecting and analyzing 32 samples located north of the old Tiouit mine (Figure $4 \mathrm{~d}$ ). The results of X-ray Fluorescence analyses clearly show significant metal concentrations (Table 1) at the structural contacts and late andesitic and rhyolitic dykes that cross the metamorphic basement Ikniwn granodiorites, which could indicate a synchronous emplacement of polymetallic mineralization. 
An examination of Table 1 shows a dominance of the metallic elements with the following values:

- The content of As varies between 0.44 and 24 ppm with an average of $4.53 \mathrm{ppm}$.

- The Cu content varies between 0.01 and $5.87 \%$, with an average of $0.76 \%$.

- Iron content varies between 0.65 and $19.30 \%$, with an average of $5.29 \%$.

- $\quad \mathrm{Pb}$ content varies between 0.02 and $5.70 \%$, with an average value of $0.47 \%$.

- Zn content varies between 0.02 and 8.85, with an average value of $0.82 \%$.

Table 1. Geochemical results of X-Ray Fluorescence analysis of samples collected in the field.

\begin{tabular}{|c|c|c|c|c|c|c|c|}
\hline $\mathbf{N}^{\circ}$ & Long $\left({ }^{\circ}\right)$ & Lat $\left(^{\circ}\right)$ & As (ppm) & $\mathrm{Cu}(\%)$ & $\mathrm{Fe}(\%)$ & $\mathrm{Pb}(\%)$ & Zn (\%) \\
\hline 1 & $-5,7985$ & 31,2443 & - & 0,80 & 2,01 & 5,70 & 8,85 \\
\hline 2 & $-5,7527$ & 31,2285 & - & 0,04 & 2,18 & 0,14 & 0,26 \\
\hline 3 & $-5,7456$ & 31,1658 & - & - & 5,08 & - & \\
\hline 4 & $-5,7467$ & 31,1681 & 2,22 & 5,87 & 9,09 & - & 0,02 \\
\hline 5 & $-5,7467$ & 31,1681 & - & 0,62 & 0,65 & - & - \\
\hline 6 & $-5,7467$ & 31,1681 & 1,43 & 3,41 & 3,29 & - & - \\
\hline 7 & $-5,7472$ & 31,1695 & 1,21 & 0,48 & 0,91 & - & - \\
\hline 8 & $-5,7472$ & 31,1695 & - & 0,22 & 1,71 & 0,04 & - \\
\hline 9 & $-5,7587$ & 31,1619 & - & - & 3,09 & - & - \\
\hline 10 & $-5,7590$ & 31,1625 & - & 0,02 & 2,59 & - & - \\
\hline 11 & $-5,7590$ & 31,1625 & - & 0,06 & 3,93 & - & - \\
\hline 12 & $-5,7590$ & 31,1625 & - & - & 8,40 & - & - \\
\hline 13 & $-5,7662$ & 31,1505 & 1,97 & 1,11 & 1,18 & 0,03 & - \\
\hline 14 & $-5,7665$ & 31,1500 & 24,00 & 2,60 & 16,60 & - & 0,02 \\
\hline 15 & $-5,7665$ & 31,1500 & - & 0,07 & 3,85 & - & - \\
\hline 16 & $-5,7669$ & 31,1515 & 1,65 & 0,06 & 6,72 & 0,05 & 0,11 \\
\hline 17 & $-5,7669$ & 31,1515 & 6,51 & 0,08 & 9,10 & 0,03 & 0,06 \\
\hline 18 & $-5,7669$ & 31,1515 & - & 0,03 & 4,67 & 0,08 & 0,03 \\
\hline 19 & $-5,7638$ & 31,1246 & - & 0,02 & 10,50 & - & - \\
\hline 20 & $-5,7638$ & 31,1246 & 4,83 & 3,90 & 8,53 & - & 0,20 \\
\hline 21 & $-5,7638$ & 31,1246 & - & - & 19,30 & - & - \\
\hline 22 & $-5,8308$ & 31,2243 & - & - & 5,65 & 0,03 & 0,15 \\
\hline 23 & $-5,8308$ & 31,2243 & - & & 5,65 & 0,03 & - \\
\hline 24 & $-5,8306$ & 31,2244 & 0,44 & 0,06 & 2,47 & 0,02 & 0,03 \\
\hline 25 & $-5,8306$ & 31,2244 & - & 0,02 & 2,11 & - & 0,03 \\
\hline 26 & $-5,8306$ & 31,2244 & - & 0,02 & 1,60 & 0,11 & 0,09 \\
\hline 27 & $-5,8079$ & 31,2238 & - & 0,03 & 6,86 & - & - \\
\hline 28 & $-5,8079$ & 31,2238 & - & 0,09 & 6,75 & - & - \\
\hline 29 & $-5,8113$ & 31,2516 & - & 0,01 & 1,20 & 0,02 & - \\
\hline 30 & $-5,8113$ & 31,2516 & 1,01 & 0,03 & 2,62 & 0,15 & - \\
\hline 31 & $-5,8113$ & 31,2516 & - & 0,03 & 3,05 & 0,17 & - \\
\hline 32 & $-5,7928$ & 31,2177 & - & 0,02 & 7,92 & - & - \\
\hline
\end{tabular}

\section{Conclusions}

The use of Principal Component Analysis in the processing of geophysical data has demonstrated its effectiveness in mining research through its contribution to the identification of new mining zones. The processing of helicopter-borne geophysical data by principal component analysis has enabled these variables' eigenvector matrix to be identified. The choice of principal component 4 allowed, in a first step, to characterize the copper porphyry type of the Tiouit mine. Secondly, X-ray 
Fluorescence analyses of samples collected in the northern part of the study area showed significant concentrations of $\mathrm{As}, \mathrm{Fe}, \mathrm{Zn}, \mathrm{Pb}$, and $\mathrm{Cu}$.

Author Contributions: Conceptualization, A.M., D.E.A. and M.A.; methodology, A.M.., D.E.A.; software, A.M., M.A.; validation, A.M., D.E.A. and A.A.; formal analysis, A.M., D.E.A. and M.A; investigation, A.M.; resources, A.A.; data curation, A.M.; writing-original draft preparation, A.A., D.E.A. and A.A.; writing-review and editing, A.M., D.E.A., A.A., and M.A.; visualization, A.M.; supervision, A.A., D.E.A.; project administration, A.A.; funding acquisition, A.M., All authors have read and agreed to the published version of the manuscript.

Funding: This research received no external funding.

Acknowledgments: The authors would particularly like to thank Mr. Manar Ahmed, Head of the Applied Geology Division at the Ministry of Energy, Mines and Sustainable Development of Morocco, for his technical support in carrying out this work.

Conflicts of Interest: The authors declare no conflict of interest.

\section{References}

1. Al Ansari, A.; Sagon, J. Le gisement d'or de Tiouit (Jbel Saghro, Anti-Atlas, Maroc) Un système mésothermal polyphasé à sulfures-or et hématite-or dans une granodiorite potassique d'âge protérozoïque supérieur, Chron. Rech. Minière 1997, 527, 3-25.

2. Ranjbar, H.; Masoumi F.; Carranza, E.J.M. Evaluation of geophysics and spaceborne multispectral data for alteration mapping in the Sar Cheshmeh mining area, Iran, Inter. J. Appl. Remote Sens. 2011, 32, 3309-3327.

3. Miftah, A.; El Azzab, D.; Attou, A.; Rachid, A.; Ouchchen, M.; Soulaimani, A.; Manar, A. Combined analysis of helicopter-borne magnetic and stream sediment geochemical data around an ancient Tiouit gold mine (Eastern Anti-Atlas, Morocco): Geological and mining interpretations. J. Afr. Earth Sci. 2021, 175, 1-12.

4. Douglas, F.H. Resistivity mapping with an airborne multicoil electromagnetic system", Geophysics 1978, 43, 144-172.

5. Minty, B.R.S. Fundamentals of airborne gamma-ray spectrometry", J. Aust. Geol. Geophys. 1997, 17, 39-50.

6. Hindermeyer, J. Le precambrien-iii du sarho", Comptes Rendus Hebd. Seances acad. Sci. 1953, 237, $1024-1026$.

7. Choubert, G. Histoire géologique du Précambrien de l'Anti-Atlas", Éditions du Service géologique du Maroc 1964.

8. Leblanc, M. Ophiolites précambriennes et gites arseniés de cobalt: Bou Azzer (Maroc). These Doctorat d'Etat, Faculte des Science Paris VI, Memoires Centre Geologique et Geophysique. 1975

9. Boyer, C.; Chikhaoui, M.; Dupuy, C.; Leblanc, M. Le volcanisme calco-alcalin précambrien terminal de l'Anti-Atlas (Maroc) et ses altérations, Interprétation géodynamique",Cr. Acad. Sci. Paris 1978, 287, 427-430.

10. Baranov, V.; Naudy, H. Numerical calculation of the formula of reduction to the magnetic pole. Geophysics 1964, 29, 67-79.

11. Huang, H.; Fraser, D.C. The differential parameter method for multifrequency airborne resistivity mapping. Geophysics 1996, 61, 100-109.

12. Valleau, N.C. HEM data processing-a practical overview. Exploration Geophysics 2000, 31, pp. 584-594.

13. Hawkins, M.P.; Beddoe Stephens, B.; Gillespie, M.R.; Lough-lin, S.; Barron, H.F.; Bames, R.P.; Powell, J.H.; Waters, C.N.; Williams, M. Carte géologique du Maroc au 1/50 000, feuille Tiouit. Notes Mémoires Service Géologique Maroc 2001, 404.

14. Bierwirth, P. N.; Brodie, R.S. Gamma-ray remote sensing of aeolian salt sources in the Murray-Darling Basin, Australia. Remote Sens. Environ. 2008, 112, 550-559.

15. Pearson, K. On lines and planes of closest fit to systems of points in space, Lond. Edinb. Dublin Philos. Mag. J. Sci. 1901, 2, 559-572.

16. Suarez-Alvarez, M.M.; Pham, D.T.; Prostov, M.Y.; Prostov, Y.I. Statistical approach to normalization of feature vectors and clustering of mixed datasets. Proceedings of the Royal Society A: Mathematical, Physical and Engineering Sciences 2012, 468, 2630-2651. 